\title{
Effects of Photographic Distance on Tree Crown Attributes Calculated Using UrbanCrowns Image Analysis Software
}

\author{
Mason F. Patterson, P. Eric Wiseman, Matthew F. Winn, Sang-mook Lee, and Philip A. Araman
}

\begin{abstract}
UrbanCrowns is a software program developed by the USDA Forest Service that computes crown attributes using a side-view digital photograph and a few basic field measurements. From an operational standpoint, it is not known how well the software performs under varying photographic conditions for trees of diverse size, which could impact measurement reproducibility and therefore software utility. Researchers evaluated the robustness of crown dimension computations made with UrbanCrowns for open-grown sugar maples (Acer saccharum) across a range of sizes from recently transplanted to full maturity. It was found that computations of both crown volume and density were highly repeatable across varying photographic distances. For the majority of tree size classes, crown volume and density varied less than $5 \%$ on average over distances ranging from $1.5 \times$ to $3.0 \times$ tree height; however, crown volume errors of 5\%-10\% were common for larger trees ( $>46 \mathrm{~cm}$ trunk diameter). UrbanCrowns calculations of crown volume showed strong agreement with calculations derived from equations for geometric solids, both in terms of precision $\left(R^{2}=0.9783\right)$ and accuracy $\left(B_{1}=1.0033\right)$. These findings suggest that UrbanCrowns has potential as an objective, reliable method for measuring tree crown attributes that are commonly assessed during urban forest inventories.

Key Words. Crown Density; Crown Transparency; Crown Volume; Leaf Area; Tree Inventory; Tree Measurement; Tree Monitoring.
\end{abstract}

Measuring tree crown attributes such as volume and density is a common procedure during the assessment and management of landscape trees. These measurements are relevant to numerous endeavors, such as monitoring tree health and vitality (Bussotti et al. 1995; Solberg 1999), evaluating tree responses to management (Kjelgren 1995; Bühler et al. 2007), and modeling tree ecophysiological functions (Donat and Ruck 1999; Buccolieri et al. 2009). Measuring crown attributes typically entails conventional physical measures or subjective visual ratings. Depending on the circumstances, these techniques can be timeconsuming, imprecise, and inaccurate, making their application impractical or unreliable - particularly for longitudinal studies (Innes 1988; Ghosh et al. 1995; Solberg and Strand 1999).

Numerous methods have been used to measure tree crown dimensions. Crown height and width can be measured directly in the field using conventional tools such as a measuring tape, clinometer, or laser hypsometer. From these measures, crown volume can be readily calculated using the formula for a geometric solid that approximates the shape of the crown. Various geometric solids, ranging from a simple sphere to a complex polyhedron have been used to model tree crown volume (Mawson et al. 1976; Brown 1978; McPherson and Rowntree 1988; Cluzeau et al. 1995; Wilkinson 1995; Baldwin and Peterson 1997; Wright et al. 2006). Crown volume estimates based on geometric solids and field measurements have been found to correlate well with leaf area (Tucker et al. 1993; Nowak 1996; Karlik and Winer 1999), which is a key parameter for modeling urban tree functions such as air pollutant interception (Nowak 1994) and rainfall storage (Xiao et al. 2000). Despite the practicality of geometric crown calculations, accuracy can be compromised when using simple geometric solids due to assumptions that the crown is symmetric and has a convex surface (i.e., there are no indentations), which is often not the case for urban trees subjected to prevailing winds, storm damage, pests, and pruning. Although complex geometric solids can improve accuracy by accounting for undulating crown surfaces (Tucker et al. 1993; Cluzeau et al. 1995), these models require additional tree measurements and intricate equations, which reduces measurement practicality.

Imaging technologies have also been employed to measure tree crown attributes. Ground-based photography has been used to reliably estimate crown height and width (Seiler and McBee 1992; Wilkinson 1994), crown silhouette area (Lindsey and Bassuk 1992), crown volume (Bignami and Rossini 1996), and crown density (Osawa and Kurachi 1997). More recently, digital imaging coupled with computer analysis has improved the precision and automation of crown measurements from photographs (Brown et al. 2000; Phattaralerphong and Sinoquet 2005). Photographic measurement of crown attributes has several potential advantages over conventional physical measures: quicker field acquisition, less observer bias, and greater reproducibility. However, even these techniques can bear limitations, such as specialized equipment needs or intensive image post-processing, which reduces their suitability for arboricultural research and practice.

UrbanCrowns is a software program developed by the USDA Forest Service Southern Research Station that calculates several tree crown attributes using a single side-view digital photograph and a few basic field measurements (Winn et al. 2007). The program provides estimates of tree height and length as well as crown height, diameter, ratio, volume, transparency, and density. Photographs can be taken with a basic digital camera, and the software can be operated on any computer running Microsoft Windows version XP or later along with Windows .NET Frame- 
work 2.0. Required field measurements include photographic angles to the top and base of the tree and horizontal distance from the photographer's position to the lower trunk of the tree.

Because UrbanCrowns is public domain software and requires no highly specialized equipment or field skills, the program has tremendous potential for improving the efficiency, accuracy, and precision of tree crown measurements. However, UrbanCrowns has received limited empirical testing. From a strictly operational standpoint, it is not known how well the software performs under varying photographic conditions for trees of diverse size, which could impact the program's practicality and measurement reproducibility. To address these questions, a field study of UrbanCrowns software was undertaken to evaluate the effect of photographic distance on crown dimension estimates for opengrown sugar maple (Acer saccharum) of various size classes.

\section{METHODS}

The field study was conducted on the Virginia Tech campus in Blacksburg, Virginia, U.S. (latitude: $37.23^{\circ}$; longitude: $-80.42^{\circ}$ ) over a two-week period in late summer 2009. Using the campus tree inventory, fifty open-grown sugar maples were purposefully selected to obtain ten trees each in five $15 \mathrm{~cm}$ trunk diameter classes $(0-15,16-30,31-45,46-60,>60 \mathrm{~cm})$. Trees in poor health or having severe crown damage were excluded from the sample. Sample trees were visited in the field to obtain digital photographs and collect physical measures. First, the surroundings of the tree were assessed to identify a photographic position that would permit the entire tree to be photographed while also minimizing foreground and background obstructions and sunlight glare. Using a measuring tape, the maximum crown diameter, both perpendicular and parallel to the photographic position was measured along with the trunk diameter at $1.37 \mathrm{~m}$ above ground line. Four photographs were taken of each tree at horizontal distances equaling $1.5 \times, 2 \times, 2.5 \times$, and $3 \times$ the tree's total height, which (along with angle to the top and base of the tree) was measured using a laser rangefinder (TruPulse 200, Laser Technology Inc., Centennial, Colorado, U.S.). Photographs were taken with a 3.1 megapixel compact digital camera (Sony Cyber-shot DSC-W5, Sony, Tokyo, Japan) set to $7.9 \mathrm{~mm}$ focal length and $\mathrm{f} / 5.6$ aperture and held plumb $1.67 \mathrm{~m}$ above ground line. All four photographs of a single tree were taken at the same azimuth, which was measured with a compass.

Tree photographs were uploaded to a desktop computer and imported to the UrbanCrowns software application. For each image, several manual inputs were made to the application to permit crown analysis by the software. Field values for the camera azimuth to tree, horizontal distance to tree, angle to crown top, and angle to trunk base were first entered. Next, three reference lines were manually digitized on the tree image (Figure 1). The first line (yellow) was drawn from the base to the top of the tree, following any lean in the stem. This line input, combined with the view angles and horizontal distance measurements from the field, scaled the photograph (determined the actual area represented by each pixel). The second line (pink) was drawn around the portion of the crown unobstructed by vegetation or structures present in the foreground and background. This region was used by the software to calculate crown transparency and density. The third line (blue) was drawn around the entire crown to roughly delineate the area for crown volume calculation. Both the crown density and crown volume reference lines were then

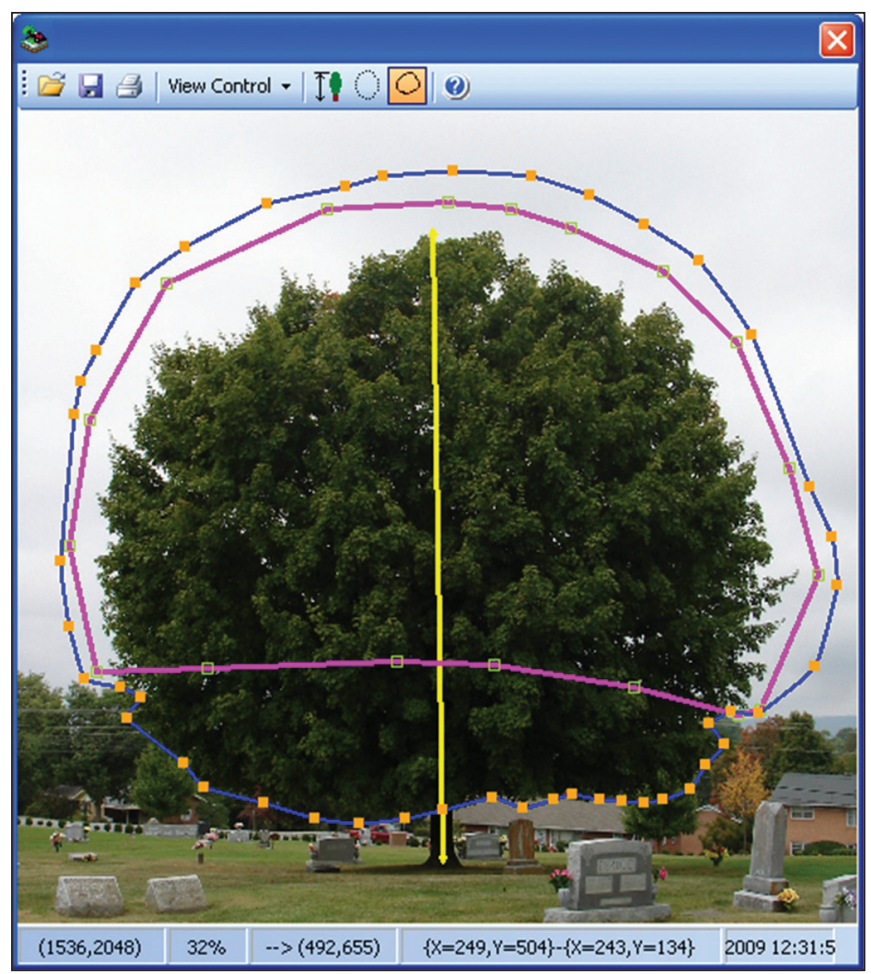

Figure 1. Screenshot from UrbanCrowns image analysis software showing reference lines digitized by the operator during the first stage of analysis: tree height (yellow), crown volume (blue), and crown density (pink). Shown here is a sugar maple (Acer saccharum), measuring $48 \mathrm{~cm}$ trunk diameter and $12 \mathrm{~m}$ tall, photographed at a distance of $24 \mathrm{~m}$.

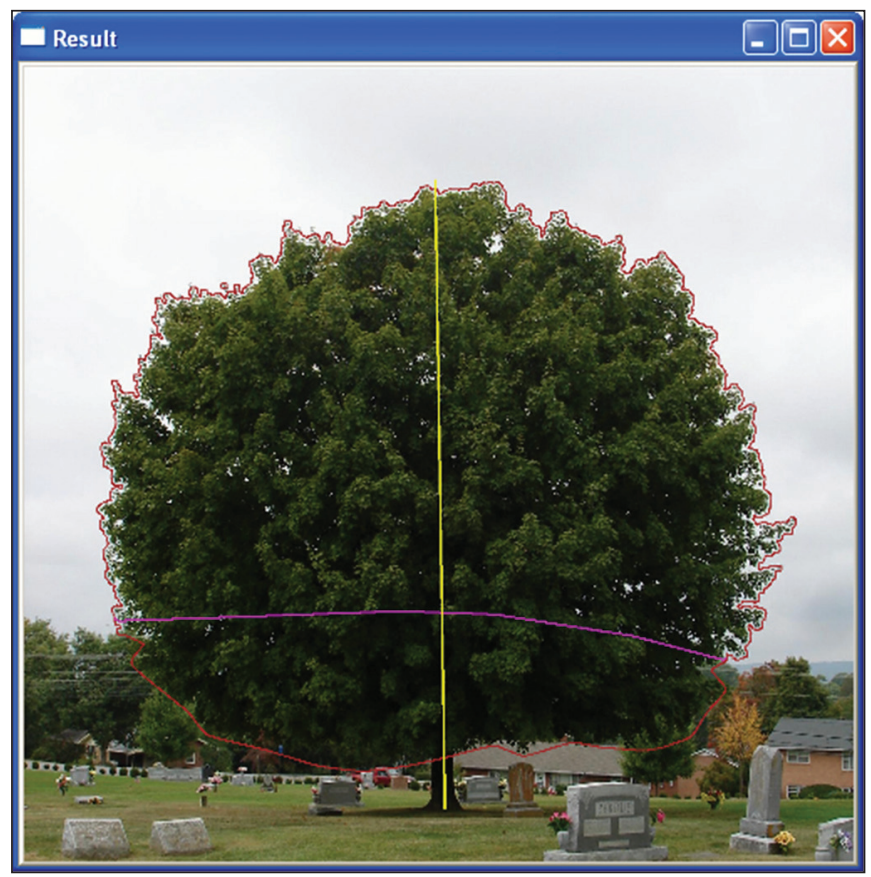

Figure 2. Screenshot from UrbanCrowns image analysis software showing computer-processed reference lines ("wrapping" of crown) made during the second stage of analysis: tree height (yellow), crown volume (red), and crown density (pink). Shown here is a sugar maple (Acer saccharum), measuring $48 \mathrm{~cm}$ trunk diameter and $12 \mathrm{~m}$ tall, photographed at a distance of $24 \mathrm{~m}$. 
wrapped tightly against the crown's surface undulations by automated computer processing (Lee et al. 2003) (Figure 2).

Once manual inputs were completed, computer analysis of the image was executed and estimates of crown dimensions were automatically calculated. UrbanCrowns calculates crown density by analyzing the relative color of each pixel within the unobstructed crown region previously digitized for this purpose. Each pixel is classified as either background (e.g., sky or building façade) or tree structure (leaves, branches, stems, and trunks). Density is then calculated as the percentage of pixels within the delineated crown region that are classified as tree structure. UrbanCrowns calculates crown volume based on the scaled width and height of each row of pixels in the delineated crown image. An imaginary cylinder is generated for each row of pixels that has a height equal to the calculated height of one pixel and a diameter equal to the calculated width of the row (i.e. crown diameter at that particular height in the crown). Calculated volumes for each row of pixels are then summed to obtain the volume estimate for the digitally delineated crown. This estimate of crown volume includes both tree structure and voids, so the program multiplies total crown volume by the crown density percentage to estimate the volume of tree structure only.

In addition to software computations, crown volume was also calculated using equations for four geometric solids, similar visually to the observed crown shapes of the sampled sugar maples: 1) sphere, (2) vertical ellipsoid, 3) circular paraboloid, and 4) conical frustum with top radius to bottom radius ratio equaling two-thirds. The equations used for these geometric solids were:

$$
\begin{aligned}
& \text { Volume }=4 / 3 \cdot \pi \cdot \mathrm{r}^{3} \\
& \text { Volume }=4 / 3 \cdot \pi \cdot \mathrm{r}^{2} \cdot \mathrm{h} \\
& \text { Volume }=1 / 2 \cdot \pi \cdot \mathrm{r}^{2} \cdot \mathrm{h} \\
& \text { Volume }=1 / 3 \cdot \pi \cdot \mathrm{h} \cdot\left[\mathrm{r}^{2}+(2 / 3 \cdot \mathrm{r})^{2}+(\mathrm{r} \bullet(2 / 3 \cdot \mathrm{r}))\right]
\end{aligned}
$$

where $r$ equals maximum field-measured crown radius perpendicular to the photographic position, and $\mathrm{h}$ equals field-measured crown height.

All statistical analyses were performed using JMP 8.0 (SAS Institute Inc., Cary, North Carolina, U.S.). Values of response variables (crown volume and crown density) were tested for normality and equal variance prior to Analysis of Variance (ANOVA). Crown volume was transformed with the cubic root and crown density with the cubic power to meet ANOVA assumptions. The effects of trunk diameter class and photographic distance on the response variables were analyzed using a $5 \times 4$ ANOVA model. Where main effects were significant, multiple comparisons of means were conducted using Tukey's HSD test at $\alpha=0.05$ significance level. One-sample t-tests were also used to test the absolute percentage differences in computed crown metrics between photographic distance intervals against hypothesized values of $0 \%, 1 \%, 5 \%$, and $10 \%$. Polynomial regression was used to model the relationship between trunk diameter and computed crown volume. Simple linear regression was used to assess the precision and accuracy of software-computed crown volume relative to crown volume calculated using geometric solids. Precision was assessed using the coefficient of determination $\left(\mathrm{R}^{2}\right)$, and accuracy was assessed using the slope coefficient
$\left(\mathrm{B}_{1}\right)$, where $\mathrm{B}_{1}<1$ indicated overestimation of crown volume by geometric calculation, and $\mathrm{B}_{1}>1$ indicated underestimation.

\section{RESULTS}

Average crown volume and density across the five trunk diameter classes ranged $22-2,743 \mathrm{~m}^{3}$ and $83 \%-92 \%$, respectively (Table 1). Crown volume was significantly greater with each incremental increase in trunk diameter class regardless of photographic distance. Crown density showed a similar pattern, but the larger diameter classes had a tendency to not significantly differ from one another. Regardless of trunk diameter class, a significant effect of photographic distance on neither crown volume nor crown density could be detected with ANOVA.

Testing absolute percentage differences in computed crown metrics between photographic distance intervals revealed that computations were highly repeatable across distances (Table 2). For crown volume, about two-thirds of the repeated computations had absolute differences of less than $5 \%$, and about one-third ranged 5\%-10\% difference. These errors had a tendency to occur in the larger trunk diameter classes and when moving over long distance intervals from the tree. The highest average error $(15.7 \%)$ occurred for the $31-45 \mathrm{~cm}$ class when moving from $1.5 \times$ to $3 \times$ tree height. Crown density showed even greater repeatability across photographic distances. Twothirds of the repeated computations had absolute differences of less than $1 \%$, and all others did not exceed $5 \%$. Crown density was most sensitive to photographic distance for smaller trees.

Crown volume showed a very strong relationship to trunk diameter for the sampled sugar maples (Figure 3). A cubic equation was found to be the best candidate polynomial model with an adjusted $\mathrm{R}^{2}$ value of $0.8901(\mathrm{P}<0.0001)$. All of the evaluated geometric solids provided precise estimates of crown volume relative to the UrbanCrowns computations (Table 3) with adjusted $\mathrm{R}^{2}$ values ranging from 0.9460 to 0.9783 (all $\mathrm{P}<0.0001$ ). Relative to the UrbanCrowns computation, the vertical ellipsoid substantially overestimated crown volume $\left(B_{1}=0.5335\right)$, whereas the circular paraboloid substantially underestimated

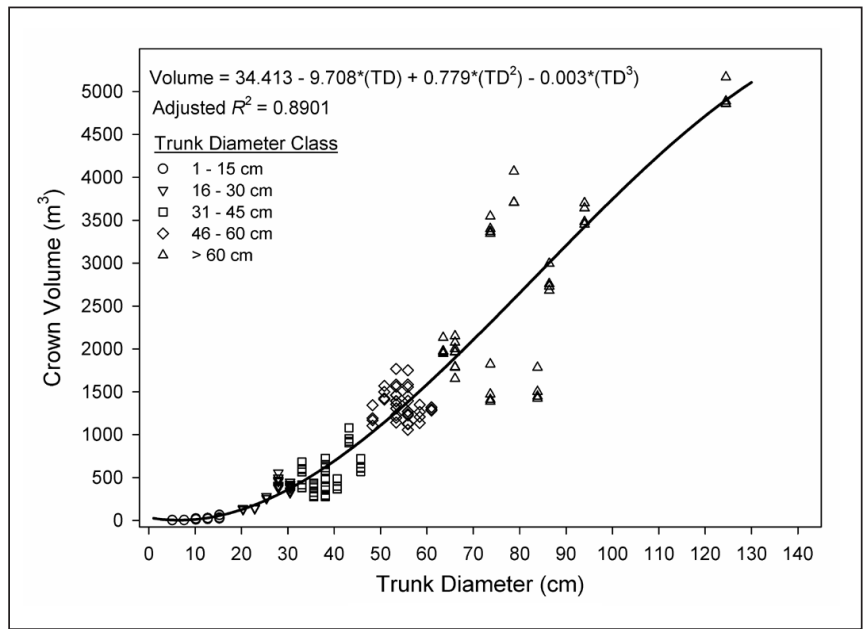

Figure 3. Polynomial regression of crown volume computed using UrbanCrowns image analysis software and trunk diameter (TD) measured at $1.37 \mathrm{~m}$ above ground line. Regression model $(P<0.0001)$ is based on measurements of 50 open-grown sugar maples (Acer saccharum). 
Table 1. Field measurements and UrbanCrowns analyses of sugar maple (Acer saccharum) sampled in urban areas of Blacksburg, VA, U.S. For UrbanCrowns analyses, trees were photographed at four horizontal distances equal to multiples (1.5x, 2.0x, $2.5 \times, 3.0 x$ ) of their individual heights. For each mean value, $n=10$ (standard error in parentheses).

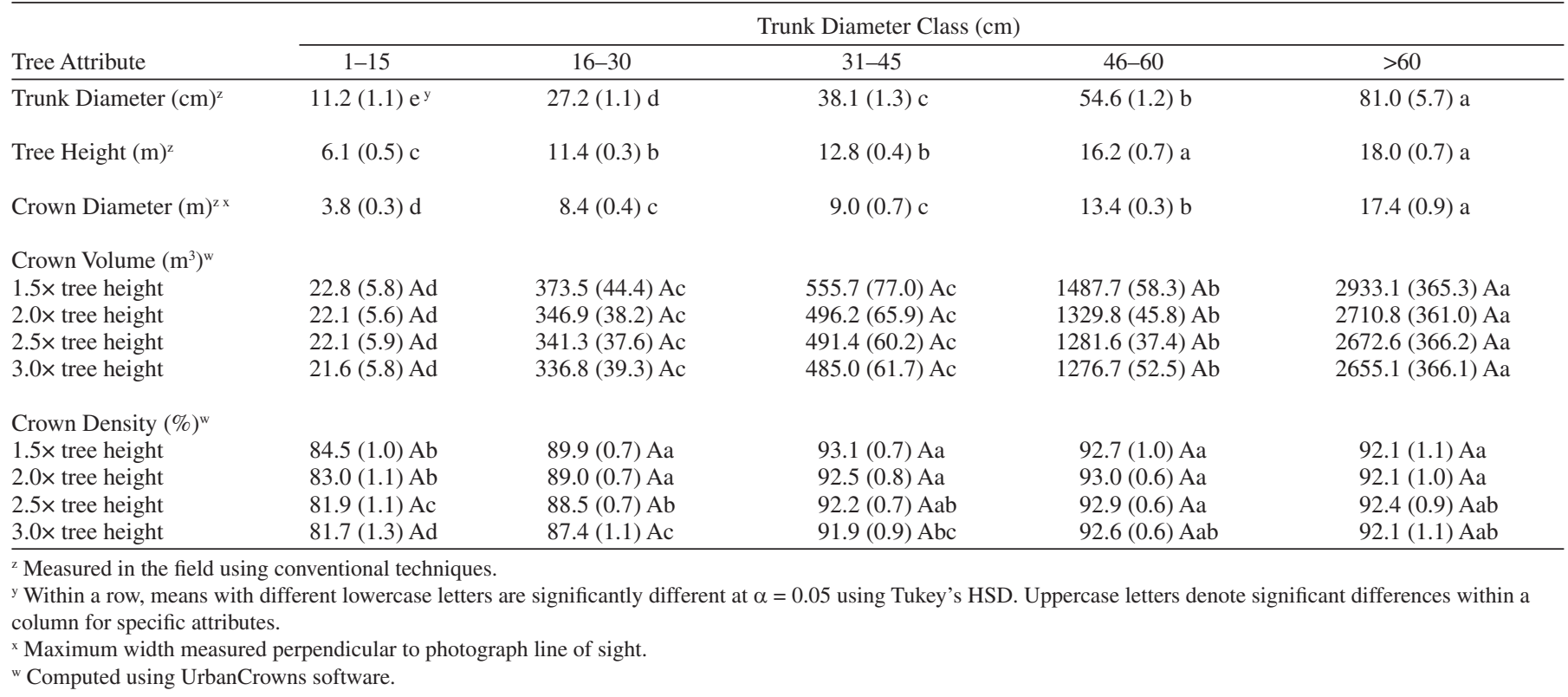

Table 2. Repeatability of UrbanCrowns estimates of crown volume and density for sugar maple (Acer saccharum) photographed at four horizontal distances equal to multiples $(1.5 \times, 2.0 x, 2.5 x, 3.0 \times)$ of their individual heights. ${ }^{*},{ }^{* *},{ }^{* * *}$, and ${ }^{* * * *}$ denote average absolute differences between paired photo distance intervals that are significantly greater than $0 \%, 1 \%, 5 \%$, and $10 \%$, respectively $(n=10$ per interval).

\begin{tabular}{|c|c|c|c|c|c|}
\hline \multirow[b]{2}{*}{ Tree Attribute } & \multicolumn{5}{|c|}{ Trunk Diameter Class (cm) } \\
\hline & $1-15$ & $16-30$ & $31-45$ & $46-60$ & $>60$ \\
\hline \multicolumn{6}{|l|}{ Crown Volume } \\
\hline $1.5 x-2.0 x$ & $* * z$ & $* *$ & $* * *$ & $* * *$ & $* * *$ \\
\hline $1.5 x-2.5 x$ & $* *$ & $* *$ & $* * *$ & $* * *$ & $* * *$ \\
\hline $1.5 x-3.0 x$ & $* *$ & $* * *$ & $* * * *$ & $* * *$ & $* * *$ \\
\hline $2.0 x-2.5 x$ & $* *$ & $* *$ & $* *$ & $* *$ & $* *$ \\
\hline $2.0 x-3.0 x$ & $* *$ & $* *$ & $* *$ & $* *$ & $* *$ \\
\hline \multicolumn{6}{|l|}{ Crown Density } \\
\hline $1.5 x-2.0 x$ & $* *$ & $*$ & $*$ & $*$ & $*$ \\
\hline $1.5 x-2.5 x$ & $* *$ & $* *$ & $*$ & $*$ & $*$ \\
\hline $1.5 x-3.0 x$ & $* *$ & $* *$ & $*$ & $*$ & $*$ \\
\hline $2.0 x-2.5 x$ & $*$ & $*$ & $*$ & $*$ & $*$ \\
\hline $2.0 x-3.0 x$ & $* *$ & $*$ & $*$ & $*$ & $*$ \\
\hline $2.5 x-3.0 x$ & $* *$ & $*$ & $*$ & $*$ & $*$ \\
\hline
\end{tabular}

${ }^{\mathrm{z}}$ Differences between paired photo distance intervals calculated as $\mathrm{I}(\mathrm{a}-\mathrm{b}) \div \mathrm{a} \times 100 \mathrm{l}$. Values tested against hypothesized means $(0 \%, 1 \%, 5 \%$, and $10 \%)$ using one-sample t-tests at $\alpha=0.05$.

Table 3. Results of simple linear regression analysis of crown volume computed using UrbanCrowns image analysis software, regressed with crown volume, and calculated using equations for geometric solids. Each regression model is based on measurements for 50 open-grown sugar maples with crown volumes ranging from $5 \mathrm{~m}^{3}$ to $5,168 \mathrm{~m}^{3}$.

\begin{tabular}{llll}
\hline & & \multicolumn{2}{c}{ Geometric solid } \\
\cline { 2 - 4 } Regression attribute & Sphere & $\begin{array}{l}\text { Vertical } \\
\text { ellipsoid }\end{array}$ & $\begin{array}{l}\text { Circular } \\
\text { paraboloid }\end{array}$ \\
\hline$P$-value $\left(\mathrm{H}_{\mathrm{o}}: B_{1}=0\right)$ & $<0.0001$ & $<0.0001$ & $<0.0001$ \\
frustum
\end{tabular}


crown volume $\left(\mathrm{B}_{1}=1.4226\right)$. Both the sphere and the conical frustum provided highly accurate estimates of crown volume relative to UrbanCrowns $\left(\mathrm{B}_{1}=1.0033\right.$ and 1.0109 , respectively).

\section{DISCUSSION}

On a strictly operational basis, UrbanCrowns software provided highly repeatable estimates of both crown volume and density across a broad range of tree sizes and showed limited sensitivity to photographic distance when photographed on a consistent azimuth. The majority of crown volume estimates had repeatability errors of less than $5 \%$ across photographic distances; errors in the range of 5\%-10\% were most common for large trees photographed across long distances. Crown density estimates were more robust with the majority of repeated measurement errors less than $1 \%$. These findings suggest that UrbanCrowns has high potential as a practical, reliable technology for assessing crown attributes of urban trees. Previous researchers have documented effective methods of estimating tree crown dimensions using photography (Miller and Lightner 1987; Seiler and McBee 1992; Wilkinson 1994; Phattaralerphong and Sinoquet 2005), but their methods typically required specialized equipment/software or substantial computer post-processing. In contrast, UrbanCrowns requires only basic photographic, mensuration, and computing equipment and minimal computer processing time. Moreover, the relatively simple field and computational measurements make the technology accessible to a broad range of skill levels. The program's robustness to varying photographic distances also makes the program particularly valuable to chronological studies where landscape changes over time may make it impossible to photograph a given tree at a consistent distance.

Although UrbanCrowns has not been subjected to computation validation through destructive sampling of trees (to determine true volume of tree structures in the crown), the high correlation of its calculations with those of geometric solids suggests that the program is reasonably accurate. Karlik and Winer (1999) found that estimates of leaf mass based on geometric solids (sphere, vertical ellipsoid, and paraboloid) were within $\sim 20 \%$ of destructively sampled leaf mass for various urban tree species. Similarly, Wright et al. (2006) found that about $80 \%$ of variability in fruit density could be accounted by modeling apple tree crown volume as an elliptical cone. In the current study, both the sphere and the conical frustum provided highly precise and accurate estimates of sugar maple crown volume relative to UrbanCrowns' computations, with the sphere being marginally superior to the frustum. These results also suggest that crown volume can be reliably estimated using trunk diameter measurement; however, these results were rendered with a carefully selected sample of trees from a single species, which limits applicability of the model. Across multiple species, tree sizes, and crown condition classes, it is suspected that UrbanCrowns would provide more reliable crown dimension estimates than equations based on either geometric solids or trunk diameter.

In addition to computation validation, there are other operational limitations of UrbanCrowns that merit consideration. First, there is the analytical assumption that the tree crown is horizontally symmetrical (i.e., circular from aerial view). Although the crowns of open-grown trees have a tendency to be symmetrical (Mawson et al. 1976; Mallette 1982), urban tree crowns may be misshapen due to storm damage, directional pruning, or crowd- ing. Currently, UrbanCrowns has no built-in feature to adjust its calculations for horizontal crown asymmetry. This limitation might be addressed by simply taking photographs from multiple angles around the tree, computing crown dimensions for each perspective, and then calculating the mean of these values. Peper and McPherson (2003) addressed this challenge in similar fashion when assessing leaf area of sycamores with crowns misshapen by constant directional winds. The researchers took two side-angle photographs of each tree crown from perpendicular perspectives and averaged the leaf area estimates calculated from each photograph. Despite substantial crown asymmetry, this photographic method produced leaf area estimates within $25 \%$ of destructively sampled leaf area on average, outperforming sophisticated digital canopy analyzers in both accuracy and precision. This approach may prove effective for analyzing misshapen crowns using UrbanCrowns and warrants further investigation.

Another operational limitation is the effect of elevation on UrbanCrowns calculations. In the current study, subject trees were chosen to minimize the effect of terrain on the analysis (i.e., trees on relatively flat ground were sampled). On uneven terrain, the effect of the photographer's elevation could compound the effects of photographic distance due to changes in the profile view of the tree.

Finally, UrbanCrowns is limited by the ability of the photographer to frame the entire crown in the image. In the current study, the closest distance practical for all tree size classes was $1.5 \times$ tree height; any closer, and it was not possible to capture the entire crown of larger trees. Although this may not be problematic for small trees, finding an unobstructed view of large trees at a distance $\geq 1.5 \times$ tree height could be a challenge in some urban settings.

\section{CONCLUSION}

Measuring tree crown attributes is an important aspect of evaluating and managing trees in the urban forest, and objective, reliable methods for obtaining these measurements are needed. In this study, the robustness of crown dimension calculations made with UrbanCrowns image analysis software was evaluated. For open-grown sugar maples across a broad range of sizes, from recently transplanted to full maturity, it was found that software computations of both crown volume and density were highly repeatable across varying photographic distances. For the majority of tree size classes, crown volume and density errors were less than $5 \%$ on average over varying photographic distances; however, crown volume errors of 5\%-10\% were common for larger trees. UrbanCrowns calculations of crown volume showed strong agreement with calculations derived from empirical equations for geometric solids and were highly correlated with trunk diameters measured in the field.

Although UrbanCrowns has great potential for field applications, practitioners should be aware of several known and potential limitations that might exist in urban settings. First, it is critical that the tree photograph be unobstructed (particularly by neighboring trees) in both the foreground and background in order to obtain accurate measurements. In addition, it is currently unknown whether the minor influence of photographic distance on crown measurements documented in this study might be exacerbated by irregular terrain, misshapen crowns, or species-specific crown geometry. Therefore, additional research is needed to fully evaluate the software's robustness to these practical limitations as well as to establish the relationship 
between its crown computations and ecologically relevant measures such as the biomass and surface area of leaves and branches.

Acknowledgments. The authors wish to acknowledge the support and cooperation of the U.S. Forest Service Southern Research Station in developing and testing the UrbanCrowns software system. The authors also thank the manuscript reviewers for their helpful comments and suggestions.

\section{LITERATURE CITED}

Baldwin, V.C., Jr., and K.D. Peterson. 1997. Predicting the crown shape of loblolly pine trees. Canadian Journal of Forest Research 27(1):102-107.

Bignami, C., and F. Rossini. 1996. Image analysis estimation of leaf area index and plant size of young hazelnut plants. Journal of Horticultural Science 71(1):113-121.

Brown, J.K. 1978. Weight and density of crowns of Rocky Mountain conifers. In USDA Forest Service Research Paper INT-197. Ogden, Utah.

Brown, P.L., D. Doley, and R.J. Keenan. 2000. Estimating tree crown dimensions using digital analysis of vertical photographs. Agricultural and Forest Meteorology 100(2-3):199-212.

Buccolieri, R., C. Gromke, S. di Sabatino, and B. Ruck. 2009. Aerodynamic effects of trees on pollutant concentration in street canyons. Science of the Total Environment 407(19):5247-5256.

Bühler, O., P. Kristoffersen, and S.U. Larsen. 2007. Growth of street trees in Copenhagen with emphasis on the effect of different establishment concepts. Arboriculture \& Urban Forestry 33(5):330-337.

Bussotti, F., M. Ferretti, A. Cozzi, P. Grossoni, A. Bottacci, and C. Tani. 1995. Crown status of holm oak (Quercus ilex L.) trees as related to phenology and environmental stress. Water, Air, and Soil Pollution 85(3):1269-1274.

Cluzeau, C., J.L. Dupouey, and B. Courbaud. 1995. Polyhedral representation of crown shape. A geometric tool for growth modelling. Annals of Forest Science 52(4):297-306.

Donat, J., and B. Ruck. 1999. Simulated ground deposition of fine airborne particles in an array of idealized tree crowns. Boundary-Layer Meteorology 93(3):469-492.

Ghosh, S., J.L. Innes, and C. Hoffmann. 1995. Observer variation as a source of error in assessments of crown condition through time. Forest Science 41(2):235-254.

Innes, J.L. 1988. Forest health surveys: problems in assessing observer objectivity. Canadian Journal of Forest Research 18(5):560-565.

Karlik, J.F., and A.M. Winer. 1999. Comparison of calculated and measured leaf masses of urban trees. Ecological Applications 9(4):1168-1176

Kjelgren, R. 1995. Variable urban irradiance and shade acclimation in Norway maple street trees. Journal of Arboriculture 21(3):145-149.

Lee, S., N. Clark, and P. Araman. 2003. Automated methods of tree boundary extraction and foliage transparency estimation from digital imagery. In: Proceedings of the 19th biennial workshop on color photography \& videography in resource assessment. Bethesda, MD: American Society for Photogrammetry and Remote Sensing. 12 pp.

Lindsey, P.A., and N.L. Bassuk. 1992. A nondestructive image analysis technique for estimating whole-tree leaf area. HortTechnology 2(1):66-72.
Mallette, J.R. 1982. Mensurational characterization of urban trees. Master's Thesis, SUNY College of Environmental Science and Forestry, Syracuse, NY.

Mawson, J.C., J.W. Thomas, and R.M. DeGraaf. 1976. Program HTVOL: The Determination of Tree Crown Volume by Layers. USDA Forest Service Research Paper NE-354. Upper Darby, PA.

McPherson, E.G., and R.A. Rowntree. 1988. Geometric solids for simulation of tree crowns. Landscape and Urban Planning 15(1-2):79-83.

Miller, S.S., and G.W. Lightner. 1987. Computer-assisted determination of apple tree canopy volume. HortScience 22(3):393-395.

Nowak, D.J. 1994. Air pollution removal by Chicago's urban forest. In: E.G. McPherson and D.J. Nowak (Eds.). Chicago's Urban Forest Ecosystem: Results of the Chicago Urban Forest Climate Project. Northeastern Experiment Station, Radnor, Pennsylvania: USDA Forest Service Technical Report NE-186.

Nowak, D.J. 1996. Estimating leaf area and leaf biomass of open-grown deciduous urban trees. Forest Science 42(4):504-507.

Osawa, A., and N. Kurachi. 1997. A light-weight CCD camera technique for estimating three-dimensional distribution of foliage density in tree crowns. Écoscience 4(2): 183-190.

Peper, P.J., and E.G. McPherson. 2003. Evaluation of four methods for estimating leaf area of isolated trees. Urban Forestry \& Urban Greening 2(1):19-29.

Phattaralerphong, J., and H. Sinoquet. 2005. A method for 3D reconstruction of tree crown volume from photographs: assessment with 3D-digitized plants. Tree Physiology 25(10):1229-1242.

Seiler, J.R., and P.N. McBee. 1992. A rapid technique for the evaluation of mature tree crown growth. Journal of Arboriculture 18(6):325-328.

Solberg, S. 1999. Crown density changes of Norway spruce and the influence from increased age on permanent monitoring plots in Norway during 1988-1997. European Journal of Forest Pathology 29(3):219-230.

Solberg, S., and L. Strand. 1999. Crown density assessments, control surveys and reproducibility. Environmental Monitoring and Assessment 56(1):75-86.

Tucker, G.F., J.P. Lassoie, and T.J. Fahey. 1993. Crown architecture of stand-grown sugar maple (Acer saccharum Marsh.) in the Adirondack Mountains. Tree Physiology 13(3):297-310.

Wilkinson, D.M. 1994. Tree mensuration using photographs. Arboricultural Journal 18(2):187-192.

Wilkinson, D.M. 1995. Modelling tree crowns as geometric solids. Arboricultural Journal 19(4):387-393.

Winn, M.F., S. Lee, and P.A. Araman. 2007. Urban tree crown health assessment system: a tool for communities and citizen foresters. In: Proceedings Emerging Issues Along Urban-Rural Interfaces II: Linking Land-Use Science and Society. pp. 180-183.

Wright, H., D. Nichols, and C. Embree. 2006. Evaluating the accountability of trunk size and canopy volume models for determining apple tree production potential across diverse management regimes. Acta Horticulturae (707):237-243.

Xiao, Q., E.G. McPherson, S.L. Ustin, M.E. Grismer, and J.R. Simpson. 2000. Winter rainfall interception by two mature open-grown trees in Davis, California. Hydrological Processes 14(4):763-784. 
Mason F. Patterson

Graduate Student

Department of Forest Resources \& Environmental Conservation

Virginia Tech

228 Cheatham Hall

Blacksburg, VA 24061-0324, U.S.

P. Eric Wiseman (corresponding author)

Associate Professor

Department of Forest Resources \& Environmental Conservation

Virginia Tech

228 Cheatham Hall

Blacksburg, VA 24061-0324, U.S.

pwiseman@vt.edu

Matthew F. Winn

Forestry Technician

USDA Forest Service, Southern Research Station

1710 Ramble Road

Blacksburg, VA 24060, U.S.

Sang-mook Lee

Post-doctoral Scientist

Bradley Department of Electrical and Computer Engineering

Virginia Tech

302 Whittemore Hall

Blacksburg, VA 24061-0111, U.S.

Philip A. Araman

Team Leader

USDA Forest Service, Southern Research Station

1710 Ramble Road

Blacksburg, VA 24060, U.S.

Résumé. UrbanCrowns est un logiciel développé par le Service forestier américain (USDA Forest Service) qui permet d'informatiser les attributs de la couronne au moyen d'une photo digitale prise de côté et de quelques mesures de base recueillies sur le terrain. D'un point de vue opérationnel, on ne connaît pas jusqu'à quel point le logiciel performe bien ou non en fonction de diverses conditions de prise de photo d'arbres de dimensions diverses, ce qui peut avoir un impact sur les mesures de reproduction et de ce fait l'utilité du logiciel en question. Les chercheurs ont évalué la robustesse des données informatisées sur la couronne obtenues à partir du logiciel UrbanCrowns, et ce pour des érables à sucre (Acer saccharum) en milieu ouvert de dimensions variées et d'âge divers (depuis ceux plantés récemment jusqu'à ceux ayant atteint leur maturité). On a découvert que les données informatisées à la fois pour le volume et la densité de la couronne étaient hautement répétitives en fonction des diverses distances de prise des photos. Pour la majorité des différentes classes de dimension, le volume et la densité de la couronne variaient de moins de $5 \%$ en moyenne par rapport aux distances de prise des photos qui correspondaient entre 1,5 et 3 fois celles de la hauteur totale de l'arbre; cependant, des erreurs de 5 à $10 \%$ dans le volume de la couronne étaient communes pour les arbres plus gros $(>46 \mathrm{~cm}$ de diamètre de tronc). Les calculs de volume de la couronne obtenus à partir du logiciel UrbanCrowns ont montré une grande fidélité par rapport à ceux obtenus à partir d'équations dérivées de solides géométriques, et ce tant en terme de précision $\left(R^{2}=0,9783\right)$ que de finesse $\left(B_{l}=1,0033\right)$. Ces observations suggèrent que le logiciel UrbanCrowns comporte un potentiel en tant que méthode fiable pour mesurer les attributs de la couronne d'un arbre qui sont normalement évalués lors d'inventaires de forêts urbaines.
Zusammenfassung. UrbanCrowns ist ein von der amerikanische Bundesbehörde für Forst und Wald entwickeltes software Programm, welches die Kronenmerkmale anhand von digitalen Seitenansichen und ein paar einfache Feldmessungen darstellt. Von einen praktischen Standort ist es nicht bekannt, wie die software unter verschiedenen Fotographie-Bedingungen für Bäume unterschiedlicher Größe arbeitet, was eine Reproduzierbarkeit der Daten und die Anwendung dieser software beeinflussen kann. Die Forscher bewerteten die Robustheit der Kronendimensiondarstellung mit UrbanCrowns für weitkronige Zuckerahorne in der Bandbreite von Jungbäumen bis zu voll ausgewachsenen Bäumen. Es wurde dabei festgestellt, daß die Darstellungen von Kronenvolumen und -dichte unter verschiedenen phototechnischen Bedingungen sehr reproduzierbar ist. Für die Mehrheit der Baumgrößenklassen variierten die Kronenvolumen und -dichten weniger als $5 \%$ bei einer durchschnittlichen Distanz von 1,5facher bis 3,0facher Baumhöhe, obwohl Kronenvolumenabweichungen von $5-10 \%$ bei größeren Bäumen $(>46 \mathrm{~cm}$ Stammdurchmesser häufig sind. Die Berechnungen von UrbanCrown zeigen eine starke Übereinstimmung mit den Berechnungen nach den Gleichungen für geometrische Körper in der Prezision $\left(R^{2}=0.9783\right)$ und Genauigkeit $\left(B_{1}=1.0033\right)$. Diese Ergebnisse verdeutlichen ein Potential von UrbanCrown als objektives und verläßliches Werkzeug zur Darstellung von Kronenattributen, die gewöhnlich während der Baumkontrollen erfasst werden.

Resumen. UrbanCrowns es un programa de software desarrollado por el Servicio Forestal de los Estados Unidos que calcula los atributos de la copa usando una fotografía digital y unos pocos datos de campo. Desde un punto de vista operativo, nos se conoce que tan bien el software trabaja bajo condiciones fotográficas variantes para árboles de diferente tamaño, lo cual podría impactar la reproducción de mediciones y la utilidad del programa. Los investigadores evaluaron la robustez de los cálculos de mediciones de la copa hechos con un UrbanCrowns para maples (Acer saccharum) a través de un rango de tamaños desde recientemente plantados a completamente maduros. Se encontró que los cálculos de ambos volúmenes y densidad de copa fueron altamente repetibles a lo largo de diferentes distancias fotográficas. Para la mayoría de las clases de tamaño de los árboles, el volumen y densidad de copa varió menos del $5 \%$ en promedio sobre distancias de $1.5 \times$ a $3.0 \times$ altura de árbol; sin embargo, los errores de volumen de copa de 5\%-10\% fueron comunes para grandes árboles ( $>46 \mathrm{~cm}$ de diámetro de tronco). Los cálculos de UrbanCrowns del volumen de copa mostraron fuerte concordancia con los cálculos derivados de ecuaciones para sólidos geométricos, tanto en términos de precisión $\left(R^{2}=0.9783\right)$ y exactitud $\left(B_{1}=1.0033\right)$. Estos hallazgos sugieren que UrbanCrowns tiene potencial como un método objetivo y confiable para mediciones de atributos de la copa del árbol que son comúnmente evaluados durante los inventarios forestales urbanos. 